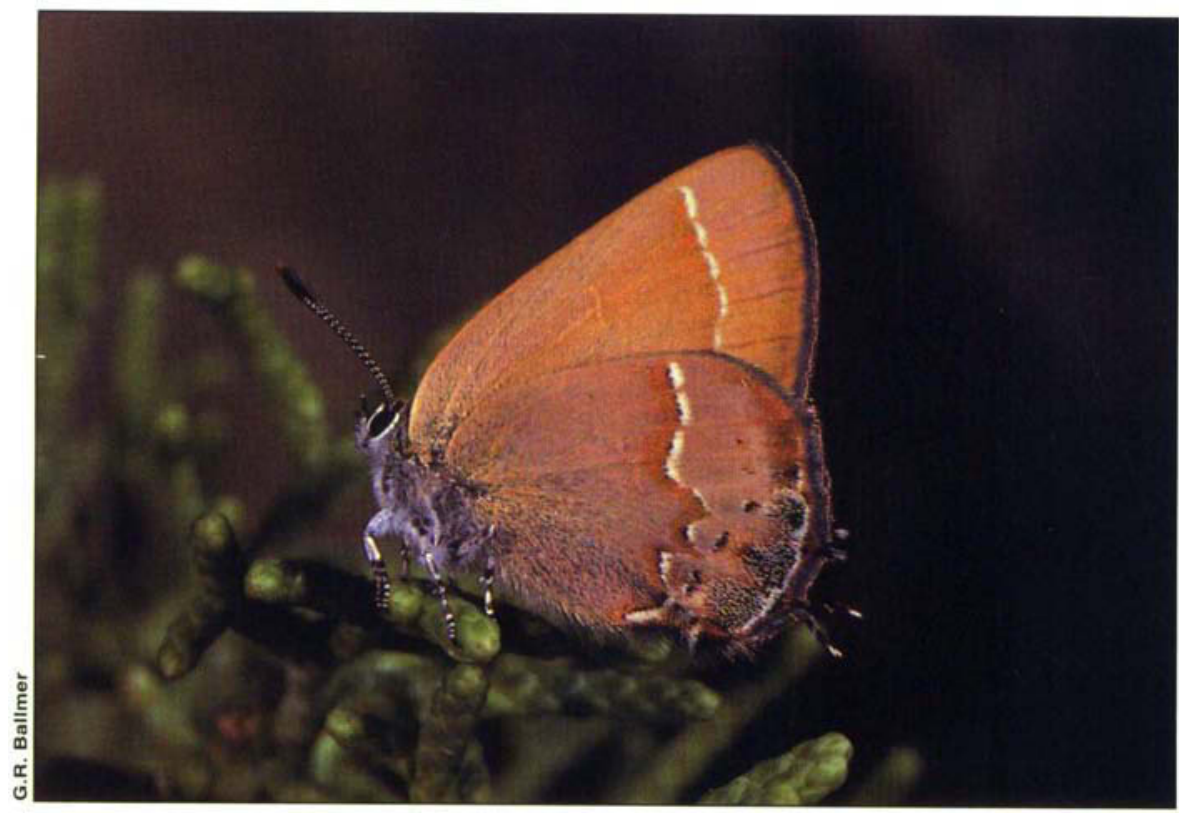

Diverse habitat are needed to preserve diverse species. Nelson's hairstreak (Mitoura ne/soni) butterfly relies entirely on $\mathrm{J}$. occidentalis and incense cedar as larval hosts.

animals than any other area of North America. Endemic species are those that are found nowhere else and California has roughly as many unique plants and animals as the rest of the 48 contiguous states put together. More than 65 vertebrates, 1,500 plants and thousands of invertebrates are endemic to the state.

California's high number of endemic species is the result of geology and climate, both of which are more complex and variable here than anywhere else in the United States. For example, the precipitation gradient from mountain to desert can range from 2 to 45 inches in less than 10 miles. Such conditions have subjected California's plants and animals to strong evolutionary forces, producing and maintaining new varieties of plants and animals at a rate that is seldom matched in other parts of the continent. Second, a number of the state's plant and animal species have also shown a profound ability to differentiate. We have over 110 species of buckwheat (Eriogonum) in California, for instance, with 85 differentiated varieties that may become species in the future.

Third, there are a number of California species that have been able to persist due to the equitable, maritime climates of coastal areas. Southern Arizona, which rivals California's mix of biomes but lacks its equitable climate (characterized by even temperatures and precipitation), has about one-fifth the number of endemic species found in Southern California and about 60 endangered species.

Like many parts of the West, California maintained much of its biodiversity well into the 20th century. Steep topography prevented the wholesale conversion of natural habitats seen in midwestern, southern, and eastern states. California agriculture had to deal with summer drought, steep slopes and thin soils; as a result, much of the state was left relatively untouched. Similarly, the impact of wildland grazing in many of the state's rare habitats was restricted by steep terrain, limited water and poor forage.

Beginning in the 1920s, however, water projects finally allowed people to develop habitats that had remained virtually unchanged since Spanish colonization in the late 1700 s. Today, California's biodiversity occurs and must be must be managed in thousands of pockets of unique habitat that are often unremarkable in their species numbers or scenic beauty. This pattern of scattered pockets has become the crux of our endangered species dilemma: a small change of land use is more likely to harm a rare species in California wildlands than in any other state. Even a small change in land use can harm a rare species or disrupt the physical and biological processes that maintain pockets of endemism.

\section{Nation's richest insect diversity in California}

\author{
Greg Ballmer
}

The broad diversity of local conditions that permit California growers to produce the broadest range of agricultural products anywhere in the United States also yield the nation's richest diversity of insects. While no one has added up the number of known insect species in California and new species are still being discovered, one conservative estimate is that there are about 27,000 insect species in California. That is roughly $30 \%$ of the estimated total for all of North America north of Mexico.

California is often likened to a biological island isolated by the Pacific Ocean on the west and by the deserts on the east. High mountain ranges further inhibit animal and plant dispersal into and out of the state. California's complex topography and its climatic gradient - which ranges from the cool, moist north coast to hot, dry southern desert - have subdivided the state into a number of biotic provinces. Each of these provinces has a fauna comprising some widespread species and many of more limited distribution.

Additionally, over geologic time, the state's climate has oscillated between subtropical and glacial extremes, causing repeated redistributions of organisms as they tracked the changing climate zones. Some insect populations adapted to the new conditions, while others became extinct or survived in isolated refugia. As a result, California contains a multitude of insects adapted to narrowly defined local conditions and isolated by geographic and ecological barriers.

Insect diversity is also closely tied to that of plants because about half of all insect species feed on plants. Moreover, many insects depend entirely on just one or a few plant species. Herbivorous insects are often further spe- 
cialized to feed primarily on one or a few plant tissues: leaves, stems, trunks, roots, flowers, seeds, or fluids. In addition to external feeders, there are leaf miners, borers, sap suckers, and gallmakers. A plant may be a host to many different insects in as many different ways.

The link between insect and plant diversity is perhaps best exemplified by bees, which are intimately associated with the evolution and diversification of flowering plants. California has over 1,600 native bee species, twice as many as occur east of the Mississippi River and nearly half of the total $(3,500)$ for North America north of Mexico. About half of California's bee species gather pollen from only one or a few related plant species. The imported European honeybee, which is used to pollinate 47 of California's agricultural crops (worth $\$ 1.5$ billion a year), adversely affects native species by competing for their floral resources. Ironically, the impending invasion of the Africanized honeybee may lead to diminished use of honeybees and increased use of native pollinators. Increased public fear of honeybees and the possibility of Africanized bees "taking over" a commercial hive may lead to greater restrictions of pollination services.

Scores of other exotic insects have also made themselves at home in California, often to the detriment of farmers, homeowners, and California's native insect fauna and flora. The alien invaders affect native species directly through competition and indirectly through the increased use of pesticides for their control. Such nonnative insects as the codling moth, silverleaf whitefly, and Mediterranean fruit fly can cause serious economic losses, entailing use of broad-spectrum pesticides for their control. Pesticide use may upset otherwise balanced natural communities by eliminating beneficial predators that normally control potential pests. These "secondary" pests can reach damaging levels and so can require further pesticide use.

There are approximately as many predatory insects as there are herbivorous species. These include mantids and other generalists and a great many host-specific parasitoid flies and wasps. However, the host specialization, which makes native parasitoids effective regulators of native prey, renders them less effective regulators of exotic pests. Scale insects, mealy bugs, whiteflies and many other exotic pests are controlled effectively by their imported natural enemies. The enlightened practice of Integrated Pest Management seeks to conserve beneficial predators and parasitoids while minimizing pesticide use. Hedgerows, roadside and ditchbank vegetation, and riparian corridors can provide reservoirs of beneficial insect diversity to recolonize agricultural fields following pesticide use or other disturbances.

The natural fertility of California's soils owes much to a third class of invertebrates, the soil-building recyclers. A large contingent of woodboring beetles, termites and scavengers is responsible for breaking down the organic matter in dead wood, fallen leaves, animal wastes and carcasses. This organic matter is further broken down by fungi and microbes into the basic nutrients utilized by plants. The recyclers do not fare well under prevailing agricultural practices, which entail frequent soil disturbance (plowing, discing) and minimal return of raw organic matter to the soil. Nor can the relatively slow action of the soilbuilding recyclers keep pace with modern agricultural crop production, which often relies on fire to reduce crop residues and fertilizer supplements to make up for nutrient loss. Fire may not directly kill soil-dwelling recyclers, but it removes nutrients they need. The chief factors that inhibit recyclers are land disturbance, monocultural production practices - as opposed to a mixed plant community and frequent changes in the type of plants grown. Because recyclers tend to be less mobile (they often lack wings) than herbivorous and predatory organisms, they are less able to become reestablished following disturbance. Minimal tillage practices, leaving land fallow for a season, and rotational use of perennial crops such as alfalfa for an extended period can benefit recyclers.

G.R. Ballmer is Staff Research Associate, Department of Entomology, UC Riverside.

\section{Reserves in California}

Can we maintain ecosystem and evolutionary processes in our biological reserves? Reserves are the linchpins of conservation in California. However, with so many unique habitats and species, we lack the financial and intellectual resources to even locate and select the habitats we should preserve, much less to purchase and manage them.

Despite 50 years of urban planning we have not succeeded in separating sensitive natural areas from suburbs and land development (fig. 1). It has become painfully obvious that many reserves cannot function because they are isolated and often damaged by outside forces. If futurists are correct, the interface between wildlands and urbanization will continue to grow as California's economy and infrastructure shift to clusters of small cities and ranchette communities such as Grass Valley in the Sierra foothills and Jamul in San Diego County. As the state's population doubles to 63 million by 2040, it will take significant energy and resources to protect reserves from the damages of exotic species, recreation seekers, non-point-source pollution, and 8-year-olds with BB guns.

\section{The conservation continuum}

Nearly all current models of reserve design include a surrounding buffer zone of low-intensity use by humans as well as habitat linkage among reserves (Dyer and Holland 1991). However, low-intensity buffer zones and linkages are virtually impossible to create in California's fragmented wildlands. This is exemplified in figure 1, which shows San Diego County wildlands fragmented by urban, suburban and ranchette development.

In San Diego County and elsewhere, urbanization has moved unevenly into wildlands, creating vast amounts of edge. In San Diego County alone, the edge between wildland and urban areas extends more than 1,400 miles. The same is true for urbanized areas such as Orange County (fig. 2) and San Francisco Bay. The size and quality of wildlands left after land development varies from large tracts of pre-European (nearly native) habitat to small, disturbed patches embedded 